Ambient Science, 2020: Vol. 07(Sp1); 86-91

DOI:10.21276/ambi.2020.07.sp1.rv01

\title{
Analysing the Effects of Vitamin D on Fibrillary Affinity of Type-II and Musculoskeletal System \\ $\underline{\text { Abstract }}$
}

\author{
Süleyman Gönülateș ${ }^{*}$, SibelTetik Dündar² \\ ${ }^{1}$ Faculty of Sport Sciences, Pamukkale University, Pamukkale, \\ Turkey \\ ${ }^{1}$ School of Physical Education and Sports, Erzincan Binali \\ Yildirim University, Erzincan, Turkeys \\ Study Area: Pamukkale, Turkey \\ Coordinates: $37^{\circ} 55^{\prime} 26^{\prime \prime} \mathrm{N} ; 29^{\circ} 07^{\prime} 24^{\prime \prime E}$
}

Key words: VDR, 1,25-dihydroxy vitamin D, Muscle Fibre Types
Vitamin D is identified as an essential vitamin serving as a primer steroid in the metabolic and biological processes in the organism. Since Vitamin D is considered as having a structure of direct-indirect effect for many processes in the organism and its capability to serve as a steroid, it can be also denominated as hormone $\mathrm{D}$.

We did an editorial study which is based on the microanalyse method, which contains the required definitions under the relevant subject scope, created by syncretizing the information, results and comments obtained from passed and actual studies. It is found that Vitamin D has effects on the muscular functions that the direct effect in respect of increase of the athletic performance (on athletes) has not become definitive, however, that's its deficiency can have negative effects on the performance. It is seen that Vitamin D deficiency has destructive effects on the muscle tissue (muscular atrophy, impairment of the cross-bridge formation, muscle weaknesses). It also causing bone mineralization disorders in adults that causes unfavourable conditions like pain and weakness in the muscles, bone pains, difficulties in walking. And it was determined, that the fibre type, which is mostly affected by such kind of negations occurred particularly in case of its deficiency, is the Type II (particularly muscular atrophy). It has also been defined, that qualified increase in the VDR (Vitamin D receptor) levels can be obtained by means of supplements provided to individuals with Vitamin D deficiency.

And considering the world population, the rate of human with Vitamin D deficiency shows incredible increases like 88\% (Bendik et al., 2014). And it is stated, that factors triggering the Vitamin D deficiency are developing depending on more like suicide situations i.e. depressive emotional and psychological disorders (Grudet et al., 2014), neural disorders, regression in mental functions (Chei etal., 2014), increase in cancer risks (Holick, 2006), depression (Polaket al., 2014).

Its deficiency causes the rickets mainly due to insensitivity towards Sunrays is determined in 1822 (Maozolowski, 1939). Thereafter it was reported that nutrition with codfish liver oil may replace the sunlight in the treatment of rickets (Mellanby, 1918) and this nutrition factor was officially defined as Vitamin D (McCollum et al.,1922).

Vitamin D is a vitamin soluble in oil and as of being particularly seen more in the elderlypopulationhowever it is seen commonly in the population (Allain \& Dhesi, 2003).

*Corresponding Author: sgonulates@hotmail.com 
discovered in the liver of the codfish (McCollum et al., 1922) it is identified as an essential vitamin serving as a primer steroid in the metabolic and biological processes in the organism (Dahlquist et al., 2015). Since Vitamin D is considered as having a structure of direct-indirect effect for many processes in the organism and its capability to serve as steroid, it can bealso denominated as hormone D.

After transformation of Vitamin D into biologically active form (1, 25-dihydroxy vitamin D) it takes the role of a regulator in the expression of many (>90o) gene variants (Wang et al., 2005). It is defined, that these expressions have important effects on many general health factors i.e., inflammation activated (induced) along exercise, tumour inhibiting genes, neural functions, cardiovascular health, sugar metabolism, bone (sufficient Ca density) health and musculoskeletal performance and onperformancebased parameters (Smith etal., 2012; Close et al., 2013).

\section{Biochemical structure and action mechanism of} the D Vitamin:

Vitamin D moves in the circulatory system via binding proteins (Holick, 2011) and shows is existence during the three-phased enzymatic reaction (25-hydroxylation, 1ahydroxylation and 24 hydroxylation) process (Bikle, 2014; Prosser \& Jones, 2004; Dahlquist et al., 2015).

Vitamin D continues its function in the body by the intermediation of the endocrinal and autocrine mechanisms. The most known of these functions is the endocrinal function, which increases the Ca absorption in the intestines and the osteoclast (cell/bone resorption catabolizing the bone tissue) activity (Owens et al., 2018). And the autocrine mechanism (path) plays role in the basic metabolic processes i.e. gene expression, protein and hormone synthesis, immunity/ inflammatory responses, positive cell cycleand synthesis (LeBoff et al., 2020).

Another situation, where the autocrine path plays a role, is its effect of Vitamin D on the musculoskeletal tissue. The reason of the intensity and studies performed recently regarding this subject is the effect of VDR's (vitamin D receptors) present in the muscle tissue. Thus, the relation of the Vitamin D and musculoskeletal system is established. The effect of the Vitamin D is realized via two mechanisms (Ceglia \& Harris, 2013). The first one is the direct effect of the $1.25(\mathrm{OH}) \mathrm{D}$ vial the VDR's in the muscle cell. The second one is the effectiveness of Vitamin D in the $\mathrm{Ca}$ binding regions, which are effective for the muscle contraction or its indirect effect in the Ca transportation in the SR (sarcoplasmic reticulum) on increasing its number (Angeline et al., 2013).

Vitamin D is also effective on the muscle protein synthesis and arrangement of the cell proliferation (cell growth), it is further effective on the muscle function via transporting $\mathrm{Ca} \& \mathrm{P}$ along the cell membrane while arranging the phospholipid metabolism (Zhang et al., 2019).
It is shown, that Vitamin D contributes also on the effectivenessof the stimulation of phosphor containing compounds on the muscle power, which occurs in result of the homeostasis and PTH (parathormone) oscillation by the effect of $\mathrm{Ca}$ on the arrangement of cell intern-extern levels(Buitrago et al., 2013). Besides, it is referred that Vitamin D may cause in an indirect manner an increase on the muscle mass and power generation by inducing the synthesis in some muscle proteins. Further it is stated, that the Vitamin D is capable to create a change in the size and number of muscle fibres of type II, that its deficiency is causing reduction of the intramyonuclear VDR gene expression level and to muscle fibre atrophy of type II, and may also support myopathy (Dzik \& Kaczor, 2019; Todd et al., 2016; Todd et al., 2015; Demirer et al., 2020).

D Vitamin and Musculoskeletal System Relation : Due to its high importance for the healthy mineralisation in skeletal system, Vitamin D has gained a vital function. Vitamin D deficiency causes some symptoms related to the musculoskeletal system, and this is confusable with musculoskeletal system disorders occurred in general (Holick, 2002; Yener, 2007).

Studies on musculoskeletal system disorders in result of verification of the VDR existence in the musculoskeletal tissue provided an evaluation potential particularly regarding the mechanical properties of the Vitamin D function (Simpson et al., 1985; Bischoff et al., 2001). Along the discovery of VDR, which is a Vitamin D receptor, the determination of its existence in different tissues, the mechanic connection between Vitamin D and its composition is also affecting many diseases and health conditions disorders (Haussler \& Norman, 1969). Some of these are; obesity, low inflammation (pyogenesis) situations, insulin resistance, metabolic syndrome, type II diabetes (McGill et al., 2008), cardiovascular risks (Kunadian et al., 2014), Dementia / Alzheimer (Littlejohns et al., 2014), depression (Jhee et al., 2017) and cancer (Garland et al., 2006).

While the VDR gene expression is at the highest level in tissues like kidney, intestines and bones, it exists in approx. 250 human tissues and all further cell types in low-mid levels (Verstuyf et al., 2010).

In a research where $\mathrm{C}_{2} \mathrm{C}_{12}$ and $\mathrm{G}_{5} 8$ cells were used, it was proved theVDR has to send signals in downward direction purposing the differentiation of myoblasts from myocytes, and at the same timethat the VDR has to be expressed in the skeletal muscles in order to protect the muscle volume (Tanaka et al., 2014).

Where the VDR has to act rapidly, the first reacting one is present on the fast-contracting muscle fibres. Thus, it is remarked that the existence and sufficiency of Vitamin D has an increasing effect on the muscle power coordination and that it is normal that it has become a factor preventing their reduction(Suzuki et al., 2008; Holick et al., 2011). 
In elder women with low mobility having an insufficient Vitamin D level, it was determined that the intramyonuclear (in the vastus lateralis muscle) VDR concentration increased in a rate of 30\% without exercise after a 4 monthly Vitamin D supplementation (Ceglia et al., 2013). In a research on rats with chronic obstructive lung disease it was determined, that the VDR expression in the extensor digitorum longus and soleus muscles of rats with Vitamin D deficiency reduced compared to rats with Vitamin D level in regular ranges (Cielen et al., 2016; Dzik \& Kaczor, 2019). Vitamin D deficiency is observed in a huge part of the population and might have harmful effects on the musculoskeletal system. Insufficient Vitamin D synthesis caused by insufficient sunlight exposure and also malabsorption occurs, which result from a Ca-poor nutrition (Wolff et al., 2008; Vieth, 1999; Öztürk et al., 2013). Vitamin D deficiency causes osteomalacia(bone mineralisation disorder) in adults. And this shows itself as pain and weakness in the muscles. Muscle weaknesses occurred accompanied by these may cause bone pains and difficulties in walking (Karadavut et al., 2003; Reginato et al., 1999). In conducted studies it is defined that the muscle fibres of type II of patients with osteomalacia myopathy are more affected from this situation (Pfeifer et al., 2002)

\section{Effects of Vitamin D on the Muscle Tissue :}

As known, the bone/ bone mineral density of athletes is higher compared to sedentary individuals. Regular physical activity/ exercise/ training ensures the development of a bone structure complying with the different body structures and changes in the body structure depending on the sport branch in which the individuals are interest and deploy (Owens et al., 2018).

Thinking with reference to the positive effect created by the exercise on the Vitamin D function (increase in the enzymatic activity) (Macdougall et al., 1998), comparing athletes with sedentary individuals, the sensitivity of athletes to Vitamin D deficiency has been considered as lesser. However, it should be considered that the sensitivity could be increased. To this extent, in a meta-analysis study, where the results of 23 different researches conducted on 2313 athletes have been interpreted, it was indicted that the Vitamin D rates in $56 \%$ of the athletes are at an insufficient level (Farrokhyar et al., 2014; Dahlquist et al., 2015).

Studies on athletes did not reveal any solid proofs showing the direct effects of Vitamin D on performance. Addressing different age groups, it was defined that intake of Vitamin D supplement increases the protection and healing of bone health and minimizes the risks of, injury and falling on the elder population. The definition of the VDR present in the muscle tissue as Vitamin D receptor caused that the subject whether the Vitamin $\mathrm{D}$ has a directindirect effect on athletes has become a matter of huge interest, and relevant studies have become more intensive (Geserick et al., 2020; Iolascon et al., 2017; Owens et al.,
2018; Demirer et al., 2020).

Muscle fibres constituting voluntary muscle contractions consist of three different types. Type I muscle fibres; are known as the fibre type, which are can contract slowly and for a long time identified as oxidative fibres and where the resistance factor is in the forefront and where intensive mitochondria and capillary (capillary vessels) setup exist; and which ensures the energy generationutilization through aerobic (oxygenated) way and where the load of the organism to perform work at low strengths for a long time is met as energy and work. Type II-a muscle fibres; are fibre types defined as fast oxidative fibres meeting the energy need mostly via aerobic ways and providing benefits also via glycolytic ways, constituting a rapid and strong contraction ability, having a lower tiredness resistance compared to type I fibres, however able to show a higher performance capacity compared to type II-x (b) muscle fibres. Type II-x muscle fibres; are fibre types defined as rapid glycolytic fibres, meeting the energy need via anaerobic (oxygen-free)ways, constituting a faster and stronger contraction ability, however developing tiredness in a short time and recognized as presenting an explosive power (Clamann \& Broecker, 1979; Dikmenoglu, 200o; Öztürk et al., 2013).

It is known, that Vitamin D has effects on muscular functions. It is possible to express this with direct effects on the protein synthesis in the muscle tissue and on the cell growth (Boland, 1986; Sørensen et al., 1979). Muscle weaknesses are generally determined in proximal muscles, while muscular atrophy (weakening, contraction) is particularly determined in type II fibres (Russell, 1994).

It is indicated that Vitamin D deficiency has destructive effects on the muscle tissue (Sato et al., 2005). These effects are explained with muscular atrophy (Glerup et al., 200o) and situations like disorders in the cross-bridge development referred in the muscle contraction theory (Pfeifer et al., 2002) and that these destructive effects may cause effects impairing and regressing indirectly the athletic performance.

\section{Conclusion:}

The direct effects of Vitamin D supplement on sport and the performance of athletes have become conclusive. However, indirectly considering the biochemical structure and effect mechanisms, it should be remembered, that the existing Vitamin D deficiency of the athlete affects the trainingcompetition performance negatively. Considering particularly its effects (protein synthesis in the muscle tissue and cell growth) on the muscular functions, it can be considered individually as an important and also supporting supplementary factor in respect of person's psychomotor skills and general performance. In studies focused on athletes it was determined that the number of ones with insufficient Vitamin D levels is predominant. However, addressing the age group, it was determined that 
the Vitamin D supplement has important effects on the elderly population in respect of protecting and improving the bone health and minimizing the risks of injury and falling.

According to results supported by studies, it is determined that type II muscle fibres are negatively affected (muscular atrophy-myopathy) particularly in case of Vitamin D deficiencies. Besides, it is cited that Vitamin D may create a difference in the size and number of type II muscle fibres. Additionally, it is remarked that Vitamin D may cause indirectly an increase of the muscle mass and power generation inducing the synthesis in some muscle proteins. However, where it is required to move quite faster, since VDR is on the first reacting, rapidly contracting muscle fibres, it is stated that it is normal, that the exigstence and sufficiency of Vitamin D has an increasing effect on the muscle power-coordination and has become as a factor preventing falling.

Reduction of the bone mineral density, which is a factor considered intensively in respect of women during the menopauses, may trigger faster and higher reductions by the destructive effect of the Vitamin D deficiency. Accordingly, particularly prioritising these periods of women, considering the vital function of VDR in the bone mineralization at all adults, it is important to regularly track and take under control the Vitamin D supplements and deficiencies. Otherwise, long term lack of tracking may cause that the motor systems suffers intensive loses in time along musculoskeletal disorders and destructions on the muscle tissue (muscular atrophy, muscle weaknesses, bone mineralization disorders, muscle and bone pains, difficulties in walking).

Considering that factors triggering the Vitamin D may also cause on long term all these negative effects (i.e. suicidality, neural disorders, regression in mental functions, increase of cancer risk and depression), it is thought that direct intake (sun, nutrition), which pioneers the elimination of the deficiency, or intake via indirect ways (medication) and supplements are important in order to prevent potential difficulties.

\section{References:}

Allain, T.J. \& Dhesi, J. (2003): Hypovitaminosis d in olderadults. Gerontology, 49:273-278.

Angeline, M.E., Gee, A.O., Shindle, M., Warren, R.F. \& Rodeo, S.A. (2013): The effects of vitamin d deficiency in athletes. Am. J. Sports Med., 41(2):461-464.

Bendik, I., Friedel, A., Roos, F.F., Weber, P. \& Eggersdorfer, M. (2014): Vitamin D: a critical and essential micronutrient for human health. Front. Physiol., 5:248.

Bikle, D.D. (2014): Vitamin D metabolism, mechanism of action, and clinical applications. Chem. Biol., 21:319-29.

Bischoff, H.A., Borchers, M., Gudat, F., Duermueller, U., Theiler, R., Stahelin, H.B. \& Dick, W. (2001): Insitudetection of 1, 25dihydroxyvitamin $\mathrm{d}_{3}$ receptor in human skeletal muscle tissue. Histochem. J., 33(1):19-24.
Boland, R. (1986): Role of vitamin d in skeletalmuscle function. Endocr. Rev., 7:434-448.

Buitrago, C., Pardo, V.G .\& Boland, R. (2013): Role of vdr in 1alpha, 25-dihydroxyvitamin d3-dependent non-genomicactivation of mapks, srcandakt in skeletalmusclecells. L. Steroid Biochem. Mol. Biol., 136:125-130.

Ceglia, L. \& Harris, S.S. (2013):Vitamin d andits role in skeletalmuscle. Calcified Tissue Int., 92(2):151-162.

Ceglia, L., Niramitmahapanya, S., da Silva Morais, M., Rivas, D.A., Harris, S.S., Bischoff-Ferrari, H., Fielding, R.A. \& DawsonHughes, B. (2013): A randomizedstudy on the effect of vitamin d 3 supplementation on skeletal muscle morphology and vitamin d receptor concentration in olderwomen. $L$. Clin.Endocrinol. Metabol., 98(12):1927-35.

Chei, C.L., Raman, P., Yin, Z.X., Shi, X.M., Zeng, Y. \& Matchar, D.B. (2014): Vitamin d levels and cognition in elderly adults in china.J.Am. Geriatr. Soc., 62(11):2125-2129.

Cielen, N., Heulens, N., Maes, K., Carmeliet, G., Mathieu, C., Janssens, W. \& Gayan-Ramirez, G. (2016):Vitamin d deficiency impairs skeletalmuscle function in a smoking mouse model. J.Endocrinol., 229(2):97-108.

Clamann, H.P. \& Broecker, K.T. (1979): Relation between force and fatig ability of redand pale skeletal muscles in man. Am. J. Physic. Med., 58:70-85.

Close, G.L., Leckey, J., Patterson, M., Bradley, W., Owens, D.J., Fraser, W.D. \& Morton, J.P. (2013):The effects of vitamin d (3) supplementation on serum total 25 [oh]d concentration and physical performance: a randomised dos response study. $\underline{B r}$. L. Sports Med., 47(11):692-696.

Dahlquist, D.T., Dieter, B.P. \& Koehle, M.S. (2015): Plausibleergogeniceffects of vitamin $d$ on athletic performance and recovery.J. Int. Soc. Sports Nutri., 12:33.

Demirer, B., Simsek, A.\&Günes, M. (2020):Theimportance of vitamin d on physicalperformance in athletes. Mediterr. J. Sport Sci. , 3(1):45-52.

Dikmenoglu, N. (200o):Skeletal muscle physiology. In: Beyazova, M. \& Kutsal, Y.G. (eds). Physical Medicine and Rehabilitation. Pub. by: Gunes Bookstore. Ankara, Turkey.

Dzik, K.P. \& Kaczor, J.J. (2019): Mechanisms of vitamin d on skeletal muscle function: oxidative stress, energy metabolism and anabolic state. Eu. J. App. Physiol., 119(4): 825-839.

Farrokhyar, F.,Tabasinejad, R., Dao, D., Peterson, D., Ayeni, O.R., Hadioonzadeh, R.\&Bhandari, M. (2014):Prevalence of vitamin $\mathrm{d}$ inadequacy in athletes: a systematic-reviewand meta-analysis. Sport Med., 45(3):365-78.

Garland, C.F.,Garland, F.C., Gorham, E.D., Lipkin, M., Newmark, H., Mohr, S.B.\&Holick, M.F. (2006):The role of vitamin d in cancerprevention. Am. J. Public Health, 96(2):252-61.

Geserick, M.,Vogel, M., Eckelt, F., Schlingmann, M., Hiemisch, A.\&Baber, R. (2020): Children and adolescents with obesity have reduced serum bone turnover markers and 25hydroxyvitamin d but increased parathyroid hormone concentrations - results derived from new pediatric reference ranges. Bone, 132:115-124.

Girgis, C.M.,Mokbel, N., Cha, K.M., Houweling, P.J., Abboud, M., Fraser, D.R., Mason, R.S., Clifton-Bligh, R.J.\&Gunton, J.E. (2014): The vitamin d receptor (vdr) is expressed in skeletalmuscle of malemiceandmodulates 25-hydroxy vitamin d (25ohd) uptake in myofibers. Endocrinology, 
155(9):3227-37.

Glerup, H.,Mikkelsen, K., Poulsen, L., Hass, E., Overbeck, S., Andersen, H., Charles, P.\&Eriksen, E.F. (2000): Hypovitaminosis d myopathy without biochemical signs of osteomalacic bone involvement. CalcifTissue Int., 66(6):41924.

Grudet, C.,Malm, J., Westrin, A. \&Brundin, L. (2014): Suicidal patients are deficient in vitamin d, associated with a proinflammatorystatus in the blood. Psychoneuroendocrinol., 50C:210-9.

Haussler, M.R. \& Norman, A.W. (1969): Chromosomal receptor for a vitamin d metabolite. Proc. Natl. Acad. Sci. USA, 62(1):155-162.

Holick, M.F. (2002):Toolittle vitamin d in premenopausal women: why should we care? Am. J. Clin. Nutr., 76:34.

Holick, M.F. (2006): Vitamin d: its role in cancer prevention and treatment. Prog. Biophys. Mol. Biol., 92:49-59.

Holick, M.F. (2011): Vitamin d: evolutionary, physiological and health perspectives. Curr. Drug Targets, 12:4-18.

Holick, M.F., Binkley, N.C., Bischoff-Ferrari, H.A., Gordon, C.M., Hanley, D.A., Heaney, R.P., Murad, M.H., Weaver, C.M. Endocrine Society (2011):Evaluation, treatment, and prevention of vitamin d deficiency: an endocrine society clinical practice guideline. J. Clin. Endocrinol. Metab., 96(7):1911-30.

Iolascon, G.,Moretti, A., De Sire, A., Calafiore, D.\&Gimigliano, F. (2017): Effectiveness of calcifediol in improving muscle function in post-menopausal women: a prospective cohort study. Adv. Therapy, 34(3):744-752.

Jhee, J.H., Kim, H., Park, S., Yun, H.R., Jung, S.Y., Kee, Y.K., Yoon, C.Y., Park, J.T., Han, H.S., Kang, S.W. \& Yoo, T.H. (2017): Vitamin d deficiency is significantly associated with depression in patients with chronic kidney disease. Plos One, 12(2):0171009.

Jones, G. (2012): Metabolism and biomarkers of vitamin D. Scand. L.Clin.Lab.Invest., 72(243):7-13.

Karadavut, K.I., Basaran, A. \& Çakci, A. (2003): Vitamin d deficiency in turkish women. Osteoporosis World, 9:74-79.

Kunadian, V., Ford, G.A., Bawamia, B., Qiu, W. \& Manson, J.E. (2014): Vitamin d deficiency and coronary artery disease: a review of the evidence. Am. Heart I., 167(3):283-291.

LeBoff, M.S., Chou, S.H., Murata, E.M., Donlon, C.M., Cook, N.R. \& Mora, S. (2020): Effects of supplemental vitamin d on bone health outcomes in women and men in the vitamin $\mathrm{d}$ and omega-3 trial (vital). J. Bone Min. Res., o(o):1-11.

Littlejohns, T.J., Henley, W.E., Lang, I.A., Annweiler, C., Beauchet, O., Chaves, P.H.M., Fried, L., Kestenbaum, B.R., Kuller, L.H., Langa, K.M., Lopez, O.L., Kos, K., Soni, M. \& Llewellyn, D.J. (2014): Vitamin D and the risk of dementia and alzheimer disease. Neurology, 83(10):920-928.

Macdougall, J.D., Hicks, A.L., Macdonald, J.R., Mckelvie, R.S., Green, H.J.\& Smith, K.M. (1998): Muscle performance and enzymatic adaptations to sprint intervaltraining. I. Appl. Physiol., 84:2138-2142.

McCollum, E.V.,Simmonds, N., Becker, J.E. \& Shipley, P.G. (1922): Studies on experimental rickets: XXI an experimental demonstration of the existence of a vitamin which promotes calcium deposition. L. Biol. Chem., 53:293-312.

McGill, A.T., Stewart, J.M., Lithander, F.E., Strik, C.M. \& Poppitt,
S.D. (2008): Relationships of low serum vitamin D3 with anthropometry and markers of the metabolic syndrome and diabetes in overweight and obesity. Nutr.J., 7:4.

Mellanby, T. (1918): Thepartplayed by an ?accessoryfactor? in the production of experimental rickets. J.Physiol., 52:11-14.

Mozolowski, W. (1939): Jedrzej sniadecki (1768-1838) on the cure of rickets. Nature, 143(3612):121.

Owens, D.J., Allison, R. \& Close, G.L. (2018):Vitamin D and the athlete: current perspectives and new challenges. Sports Med., 48(1):3-16.

Pfeifer, M.,Begerow, B. \& Minne, H.W. (2002):Vitamin d and muscle function. Osteoporos Int., 13(3):187-94.

Polak, M.A., Houghton, L.A., Reeder, A.I., Harper, M.J. \& Conner, T.S. (2014): Serum 25-hydroxyvitamin d concentrations and depressive symptoms among young adult men and women. Nutrients, 6:4720-4730.

Prosser, D.E. \& Jones, G. (2004): Enzymes involved in the activation and inactivation of vitamin D. Trends Biochem. Sci., 29:664-673.

Reginato, A.J.,Falasca, G.F., Pappu, R., McKnight, B. \& Agha, A. (1999): Musculoskeletal manifestations of osteomalacia: report of 26 cases and literature review. Semin Arthritis Rheum., 28:287-304.

Russell, J.A. (1994):Osteomalacicmyopathy. Muscle Nerve, 17:578580.

Sato, Y., Iwamoto, J., Kanoko, T. \& Satoh, K. (2005): Low-dose vitamin d prevents muscularatrophy and reduces falls and hipfractures in women after stroke: a randomized controlled trial. Cerebrovasc. Dis., 20:187-92.

Simpson, R.U., Thomas, G.A. \& Arnold, A.J. (1985): Identification of 1,25-dihydroxy vitamin $\mathrm{d}_{3}$ receptors and activities in muscle. J. Biol. Chem., 26o(15):8882-8891.

S?rensen, O.H., Lund, B., Saltin, B., Lund, B., Andersen, R.B., Hjorth, L., Melsen, F. \& Mosekilde, L. (1979): Myopathy in bone Loss of ageing: improvement by treatment with 1 alphahydroxy cholecalciferol and calcium. Clin. Sci. (Lond), 56(2):157-161.

Suzuki, T., Kwon, J., Kim, H., Shimada, H., Yoshida, Y., Iwasa, H. \& Yoshida, H. (2008): Low serum 25-hydroxy vitamin D levels associated with falls among Japanes ecommunity-dwelling elderly. J. Bone Miner. Res., 23(8):1309-1317.

Tanaka, M.,Kishimoto, K.N., Okuno, H., Saito, H. \&Itoi, E. (2014): Vitamin d receptor gene silencingeffects on differentiation of myogeniccelllines. Muscle Nerve, 49(5):700-708.

Todd, J.J., Pourshahidi, L.K., McSorley, E.M., Madigan, S.M. \& Magee, P.J. (2015): Vitamin d: recent advances and implications for athletes. Sports Med., 45(2):213-229.

Todd, J.J., Madigan, S., Pourshahidi, K., McSorley, E., Laird, E. \& Healy, M. (2016): Vitamin d status and supplementation practices in elite irish athletes: an update from 2010/2011. Nutrients, 8(8):485.

Wang, T.T., Tavera-Mendoza, L.E., Laperriere, D., Libby, E., MacLeod, N.B., Nagai, Y., Bourdeau, V., Konstorum, A., Lallemant, B., Zhang, R., Mader, S. \& White, J.H. (2005): Large-scale in silico and micro array-based identification of direct 1, 25-dihydroxy vitamin d3 target genes. Mol. Endocrinol., 19(11):2685-2695.

Willis, K.S., Smith, D.T., Broughton, K.S.\&Larson-Meyer, D.E. (2012): Vitamin d status and biomarkers of inflammation in 
runners. Open Access J. Sports Med., 3:35-42.

Wolff, A.E., Jones, A.N. \& Hansen, K.E. (2008): Vitamin d andmusculoskeletalhealth. Nat. Clin. Pract. Rheumatol., 4:580-588.

Verstuyf, A.,Carmeliet, G., Bouillon, R. \&Mathieu, C. (2010): Vitamin d: a pleiotropic hormone. Kidney Int., 78(2):140-145.

Vieth, R. (1999):Vitamin d supplementation, 25-hydroxyvitamin d concentrations, andsafety. Am. J. Clin. Nutr., 69:842-56.
Yener, M. (2007): Investigation of the relationship between musculo skeletal system pain and vitamin d levels. Süleyman Demirel Univers. Fac. Med. J., 14(4):7-11.

Zhang, L., Quan, M. \& Cao, Z.B. (2019): Effect of vitamin d supplementation on upper and lower limb muscle strength and muscle power in athletes: a meta-analysis. PlosOne, 14(4):0215826.

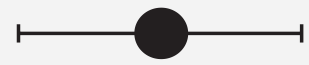

